\title{
Application of Viscous Dampers in Seismic Rehabilitation of Steel Moment Resisting Frames
}

\author{
Mohammad Hossein Saghafi ${ }^{1, a}$, Seyed Amin Eldin Movehedin ${ }^{2, b}$ and Ali Golafshar ${ }^{3, c}$ \\ 1,2,3 Depertment Civil Engineering,Semnan Brach,Islamic Azad University,Semnan,Iran \\ asaghafimh@yahoo.com, baminmovahedian1363@gmail.com, ${ }^{c}$ ali78.golafshar@gmail.com
}

\begin{abstract}
In structural seismic rehabilitation, the structural capacity spectrum curve can be enhanced by increasing the stiffness and strength of the structures and also the application of the energy dissipation systems such as dampers can decrease the structural demand spectrum curve. Dampers are basically used to mitigate the structural response and decrease the damages to the main structural elements under severe earthquakes through energy dissipation. At the present paper, it is aimed to evaluate the seismic behavior of two conventional steel moment resisting frames having 4, 8 stories incorporating seismic strength imperfection equipped with viscous dampers. OpenSees and nonlinear time-history analysis incorporating seven seismic records have been used to define the frame response. The results revealed that the seismic response of rehabilitated frames has been considerably improved. Where, the maximum roof displacement, the maximum story drift, the maximum floor acceleration and shears have been declined in damper equipped frames and the seismic performance of the most rehabilitated frame elements under an earthquake having return period of 475 years has been upgraded to performance level of life-safety.
\end{abstract}

\section{Introduction}

The structures which have been designed based on current existing codes are assumed to absorb the seismic energy through yielding or failure of the materials. For instance, the seismic energy in steel moment resisting frames is absorbed by developing of plastic hinges in beams and columns. Therefore, it can cause damages to the structural elements and also develop structural damages. So, the concentration of seismic energy dissipation in some specific devices such as dampers can reduce the damages in main structural elements and facilitate the operation of the structure after occurrence of earthquake. The viscous dampers are energy dissipating systems that are widely used in structural design and rehabilitation.

At the present research, it is aimed to investigate the application of viscous dampers in seismic rehabilitation of steel moment resisting frames. At this study, the OpenSees, one of the best software to do nonlinear structural analysis under seismic loads, have been used and seven earthquake records are used to investigate the structural behavior.

\footnotetext{
* Corresponding author: saghafimh@yahoo.com
} 


\section{Viscous Damper}

The configuration of liquid viscous dampers is generally composed of a piston and a cylinder which the viscous liquid in cylinder is compressed by the piston. The load application to the system gradually transfers the viscous liquid via small openings on the piston which can dissipate the large amount of energy.

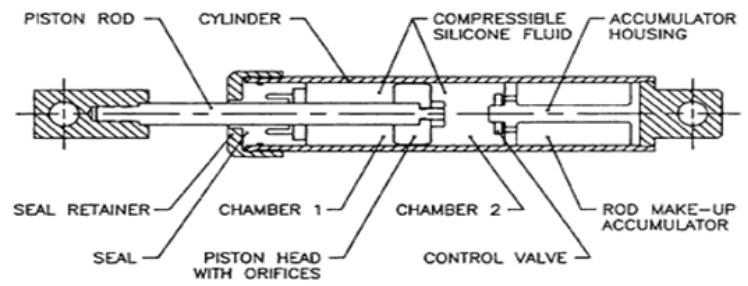

Fig. 1 composed of a piston

According to Fig. 2, these dampers are connected to the structure by means of chevron, diagonal and K-bracings.

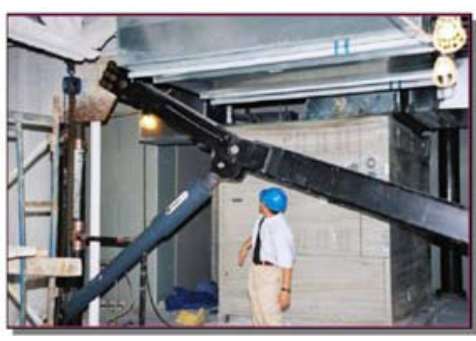

Damper installation in K-bracing

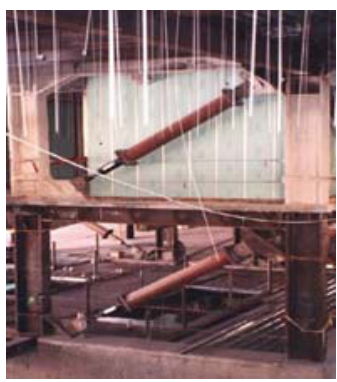

Damper installation in diagnal bracing

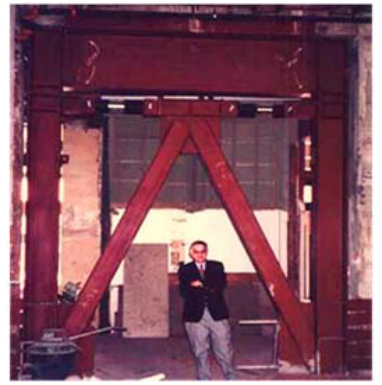

Damper installation in chevron bracing

Fig. 2- Damper configuration in frames

The relationship between the viscous damper force and the velocity is as follows:

$F_{\text {damper }}=C V^{\alpha}$

Where, $F_{\text {damper }}$ is the damper force, $\mathrm{C}$ is the damping coefficient, $\mathrm{V}$ is the relative velocity of both ends of the damper, $\alpha$ is the power of the velocity $(0.3 \sim 1)$. If $\alpha=1$, the relationship between the velocity and the damping force is assumed linear and if else, it is considered nonlinear.

\section{Analytical Model}

While the steel structures are considered in this rehabilitation study, two steel structures with less ductility having four and eight stories have been evaluated based on old version of the standard code. The height of the stories has been considered $3.5 \mathrm{~m}$ in all specimens. The number of the spans in all specimens has been considered 3 spans with the length of $5 \mathrm{~m}$. Also, the structures have been considered as residential buildings located in Tehran having soil condition of Type II in accordance with Iranian code of practice for seismic resistant design of buildings (standard no 2008). The structural system is considered as conventional 
steel moment resisting frame and the solid floor is Joists and filler block. The Dead and live load of the stories are considered 6 and $2 \mathrm{kN}$, respectively. And the seismic effective load is considered as the summation of the dead load and 20 percent of live load. The yielding strength of the steel is considered $240 \mathrm{MPa}$.

At the present research, the two dimensional models have been considered. The plan and the section details of the four and eight story frames are shown in Fig 3 and 4, respectively.

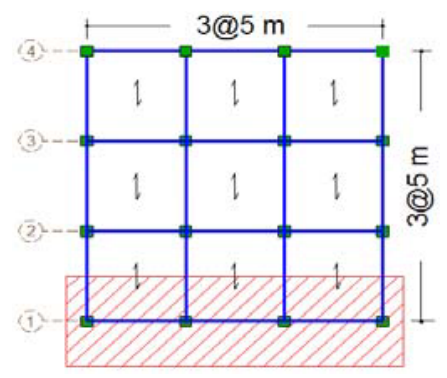

Fig. 3- Plan of the selected structure and frame
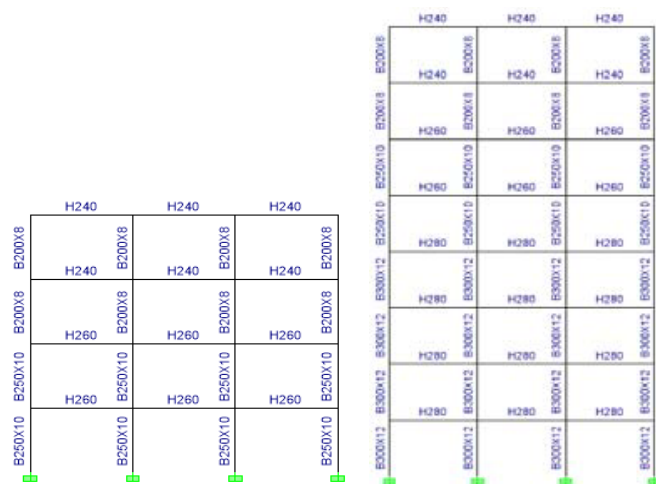

Fig. 4- Details of the studied frame sections

\section{Nonlinear Dynamic Analysis}

At the present research, seven records containing Kern county, San Fernando, Landers, Northridge, Tabas, Avoj and Bam far fault records have been used. All acceleration records are considered on soil type II.

The acceleration records have been scaled in accordance with acceleration response spectrum and the presented method in Iranian code of practice for seismic resistant design of buildings (standard no 2008-3rd edition). It is required to define the scale factor due to differences in periods of selected structures. Therefore, the maximum spectrum acceleration of selected acceleration records for four and eight story frame is considered as $0.48 \mathrm{~g}$ and 0.53 , respectively. 


\section{Seismic Evaluation}

At this section, the effective outputs of seismic evaluation of studied frames such as roof displacement, story acceleration, story drifts are presented. Using seven records of earthquake and based on rehabilitation criteria manuals, the average maximum responses have been used to estimate the response of the frames.

\section{Maximum Roof Displacement}

According to Fig 5, the maximum roof displacement of the frames with and without damper under selected acceleration records is shown. The results shows that average maximum roof displacement under seven acceleration records in four and eight story frames equipped with damper is decreased $36 \%$ and $39 \%$, respectively, rather than frames without damper.

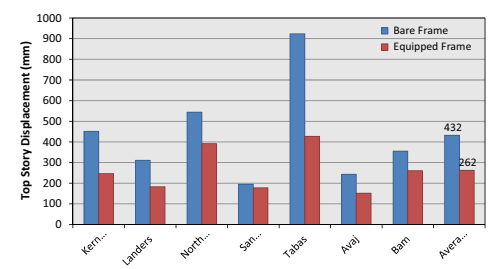

b) 8 story frame

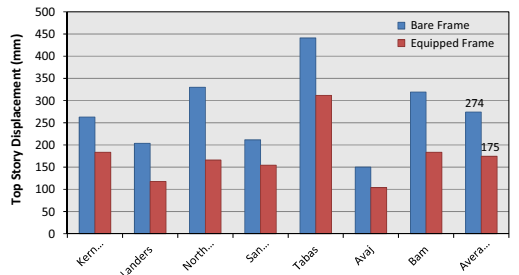

a)4 story frame

Fig. 5- Maximum roof displacement of frames

\section{Maximum Story Displacement}

According to Fig 6, the maximum story displacement of the frames with and without damper is shown. The results shows that existing maximum acceleration in four and eight story frames is decreased $24 \%$ and $25 \%$, respectively. Consequently, the damages due to throwing of nonstructural elements during earthquake and also the value of input energy are decreased.

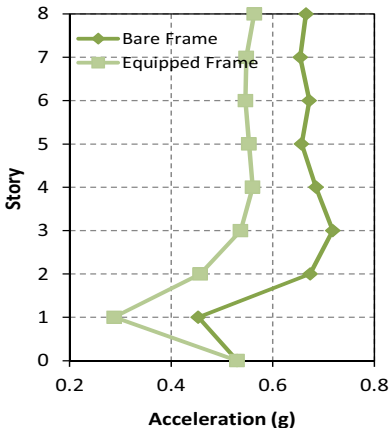

b) 8 story frame

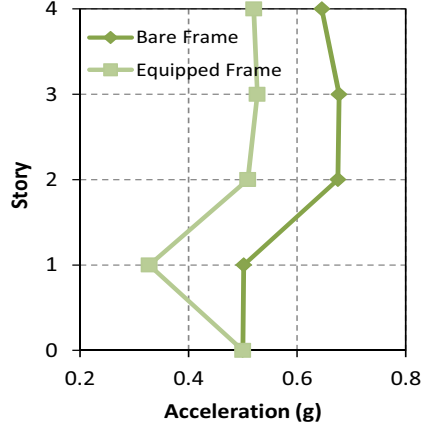

a)4 story frame

Fig. 6- Maximum story acceleration 


\section{Story Drift}

According to Fig 7, the average story drift of rehabilitated frames and base frames under seven selected records have been compared. As it can be seen the maximum story drift in four and eight story rehabilitated frames is decreased $56 \%$ and $64 \%$, respectively. Also, the drift distribution at different stories of structure equipped with damper has been constant which revealed that the damages at different stories have been reduced and the damage distribution in structure has been constant.

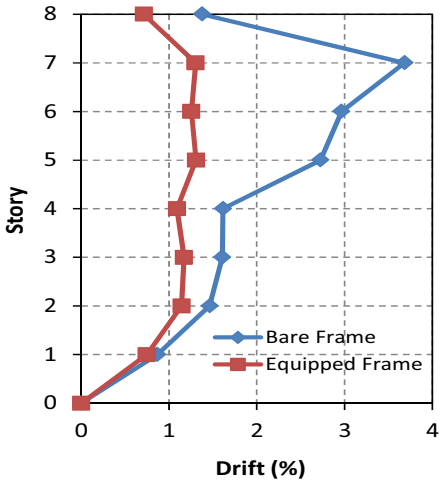

b) 8 story frame

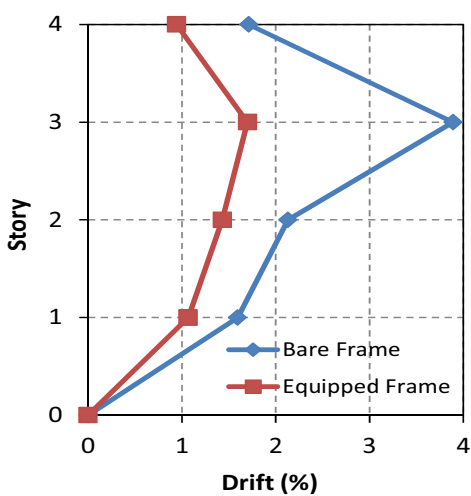

a)4 story frame

Fig. 7- Average maximum story drift

\section{Conclusions}

At the present paper, the influence of viscous dampers on seismic response of steel moment resisting frames has been studied. The results of this study are summarized as follows.

- Adding viscous dampers to the studied frames has caused a reduction in maximum roof displacement and permanent displacement while the average maximum roof displacement under seven acceleration records in four and eight story frames equipped with damper has been decreased $36 \%$ and $39 \%$, respectively.

- Using such dampers reduce and make the different story drifts constant while the maximum story drift in rehabilitated four and eight story frames has been decreased $56 \%$ and $64 \%$, respectively.

- The maximum roof acceleration and story acceleration has been reduced by using such dampers while the existing maximum acceleration in four and eight story frames equipped with dampers has been decreased $24 \%$ and $25 \%$, respectively.

- The values of story shear and base shear of rehabilitated frames are reduced due to an increase in damping of the structure.

\section{References}

1. Building and Housing Research Center, Iranian code of practice for seismic resistant design of buildings (standard no 2008-3rd edition), (2005)

2. Iranian Management \& Planning Organization, Seismic Evaluation and Retrofit of Existing Buildings , (2006) 
3. Ghanbari, A, Banazadeh, M, Seismic performance of steel structures designed by linear and nonlinear viscous damper with identical damping ratio, 10th International Conference on Civil Engineering, Tabriz, Iran , (2015)

4. FEMA, Prestadard and Commentary for the Seismic Rehabilitation of Buildings, FEMA356, Federal Emergency Management Agency, New York, (2000).

5. Mazzoni, S., McKenna, F., Scott, M.H., Fenves, G.L. OpenSees Command Language Manual, Pacific Earthquake Engineering Research Center, University of California, (2007), Available from: http://opensees.berkeley.edu/.

6. Hwang, Jenn-Shin and Huang, Yin-Nan and Yi, Shy-Lian and Ho, Song-Yen,"Design Formulations for Supplemental Viscous Dampers to Building Structures,"Journal of Structural Engineering, (2008) Vol. 134, No. 1, pp. 22-31, ISSN 0733-9445/2008/1-22-31.

7. Lu, Yun-xiang and Cai, Yuan-qi and Qu, Qing-fei and Zhan, Qian-hua,"Study on the Effect of Supporting Stiffness on Energy Dissipation Efficiency of Viscous Dampers,"Applied Mechanics and Materials (2012) Vols. 105-107, pp 96-101.

8. Akcelyan, S., and Lignos, D.G. "Adaptive Numerical Method Algorithms for Nonlinear Viscous and Bilinear Oil Damper Models Under Random Vibrations”, ASCE Journal of Engineering Mechanics (2015) 